\title{
Band alignment of front contact layers for high-efficiency CdTe solar cells
}

\author{
J.M. Kephart ${ }^{\mathrm{a}}$, J.W. McCamy ${ }^{\mathrm{b}}$, Z. Ma ${ }^{\mathrm{b}}$, A. Ganjoo ${ }^{\mathrm{b}}$, F.M. Alamgirc ${ }^{\mathrm{c}}$, W.S. Sampath ${ }^{\mathrm{a}}$ \\ ${ }^{a}$ Department of Mechanical Engineering, Colorado State University, 1320 Campus Delivery, Fort Collins, Colorado 80501 USA \\ ${ }^{b}$ PPG Industries, Inc., 400 Guys Run Road, Cheswick, Pennsylvania 15024 USA \\ ${ }^{c}$ School of Materials Science and Engineering, Georgia Institute of Technology, 771 Ferst Drive, N.W., Atlanta, Georgia
}

30332-0245 USA

\begin{abstract}
Resistive oxide materials play an important role in the front contact of CdTe solar cells. The highresistance transparent (HRT) or "buffer" layer has been used extensively in CdTe thin-film photovoltaics to enable a reduction in $\mathrm{CdS}$ thickness while maintaining near-maximum device voltage and fill factor. $\mathrm{SnO}_{2}-$ and $\mathrm{ZnO}$-based alloys were tested as HRT layers on a fluorine-doped tin oxide transparent conducting oxide. $\mathrm{SnO}_{2}$-based alloy HRT layers were deposited via atmospheric pressure chemical vapor deposition (APCVD). Alloying $\mathrm{ZnO}$ with $\mathrm{MgO}$ to create $\mathrm{Mg}_{x} \mathrm{Zn}_{1-x} \mathrm{O}(\mathrm{MZO})$ via radio-frequency sputter deposition was explored as a way to reduce the electron affinity of ZnO HRT layers. To fully understand the behavior of these materials, many devices were fabricated with either no CdS layer, a sublimated CdS layer, or a sputtered, oxygenated CdS layer. MZO layers resulted in high open-circuit voltage and device efficiency even with the complete elimination of the CdS layer. In both HRT systems, controlling electron affinity to optimize front contact band alignment is an important consideration. Band measurements using photoelectron spectroscopy and synchrotron techniques correlate band alignment measurements with efficiency parameters in the design of HRT and CdS layers.

Keywords: thin-film photovoltaics, radio frequency sputter deposition, transparent conducting oxides, UV photoelectron spectroscopy, II-VI semiconductors
\end{abstract}

\section{Introduction}

8 parent conducting oxide (TCO). Another oxide layer, dubbed the high-resistance transparent (HRT) or "buffer" layer, is often deposited on the TCO. "Highresistance" does not necessarily mean insulating but orders of magnitude more resistive than the TCO. Typically, a CdS-based layer is deposited on the HRT. $\mathrm{CdS}$ is a strong absorber of light with energy above 
its bandgap of $2.4 \mathrm{eV}$, and light absorbed in this layer ${ }_{46}$ is wasted because carriers photogenerated in the $\mathrm{CdS}_{47}$ are not collected. When the CdS layer is too thin the 48 operating voltage of the cell degrades, so the $\mathrm{CdS}_{49}$ thickness that optimizes efficiency must balance cur- 50 rent and voltage at the maximum power point.

Empirically, the presence of an HRT layer has 52 been shown to lessen the degradation in voltage as 53 the CdS thickness is decreased, allowing a thinner ${ }_{54}$ CdS layer and higher optimum efficiency. While the 55 resistance of the layer plays a role in its effect, not all 56 resistive oxides are effective HRT layers, and other 57 electronic properties must also be considered. A re-58 cent review by Klein explains the science of interface 59 band alignment in chalcogenide semiconductors and 60 discusses the CdS/CdTe interface as well as differ-61 ent oxides used as HRT layers [3]. In previous work 62 by the authors, a highly transparent oxygenated $\mathrm{CdS}{ }_{63}$ layer was shown to be compatible with one $\mathrm{SnO}_{2}{ }^{-64}$ based HRT and the importance of band alignment 65 for the oxygenated CdS layer was shown [4]. Here, 66 a combination of numerous device results, model- 67 ing, and band measurements show the importance of 68 band alignment using HRT layers within the zinc ox- 69 ide and tin oxide systems. Cells are demonstrated 70 using oxide layers that allow for high efficiency with 71 the elimination of the CdS layer.

The most commonly used TCO in commercial ${ }_{73}$ CdTe cells is fluorine-doped $\mathrm{SnO}_{2}$ (FTO) because 74 it can be deposited during the glass manufacturing 75 process with high throughput and is mostly inert to 76 subsequent processing steps. Still, cells have successfully been made using $\mathrm{In}_{2} \mathrm{O}_{3}: \mathrm{Sn}$ [5], $\mathrm{Cd}_{2} \mathrm{SnO}_{4}$ [6], and $\mathrm{ZnO}: \mathrm{Al}$ [7]. Many TCO/HRT combinations have been studied, with HRT layers including $\mathrm{ZnO}$ [8], $\mathrm{In}_{2} \mathrm{O}_{3}[9,10], \mathrm{Ga}_{2} \mathrm{O}_{3}$ [9], $\mathrm{SnO}_{2}[11,9,10,12]$, and alloys of these materials such as zinc stannate $[13,14]$. A universally described feature of these layers is their increased resistivity relative to the TCO.

One hypothesis of the HRT's role in CdTe solar cells considers the effect of pinholes, or small areas where there is no CdS coverage, and through which CdTe directly contacts the oxide layer. According to this explanation, a diode with maximum open-circuit voltage and fill factor will be formed regardless of layer thickness as long as there are no $\mathrm{CdS}$ pinholes. The pinhole area that contacts the oxide below is a weaker diode with high forward current and low open-circuit voltage [9]. A loss in open-circuit voltage occurs when CdS thickness is reduced, and this is ascribed to an increasing fractional pinhole area the substrate [12]. This theory assumes that pinhole area increases as overall CdS layer thickness decreases. By adding an ohmic resistor between the TCO and the $\mathrm{CdS}$, the theory states, less $\mathrm{CdS}$ is required because the shunting effect of the pinhole area is reduced.

In devices made at Colorado State University there is no evidence that the existence of pinholes is correlated with CdS layer thickness [15]. Electron microscopy has shown that films $20-30 \mathrm{~nm}$ thick have coalesced grains without exposing the TCO. Thick- 
nesses of close to $100 \mathrm{~nm}$ of this CdS material are 107

needed to obtain maximum open-circuit voltage. Sta-108

tistical measurements have not shown an increase in 109

pinhole area with reduced $\mathrm{CdS}$ thickness for films 10

made at CSU . Devices that have both lower pinhole 11

area and reduced $\mathrm{CdS}$ thickness nevertheless show 12 lower $\mathrm{V}_{O C}$ relative to a control, indicating that $\mathrm{CdS}_{113}$ layer thickness is an important variable independent ${ }_{14}$ of pinholes [16]. Overall, the role of the HRT has 15 not been considered clear or fully understood with w $_{16}$ yet another possibility involving the effects of ther-117 mal expansion [17]. Further understanding of which ${ }_{18}$ material properties affect HRT function is needed tor19 find more ideal contacts which allow the most lighti20 possible to reach the absorber. Here, band alignmenti21 of the front contact layers, which is known to be im-122 portant but seldom discussed in this context, is inves-123 tigated as a key concept to complement the existing ${ }_{124}$ understanding.

\section{Material and Methods}

All devices reported in this work fall within the $\mathrm{e}^{128}$ following structure: the glass is $3.2-\mathrm{mm}$ soda-lime ${ }^{129}$ glass, the TCO is fluorine-doped tin oxide, the $\mathrm{HRT}^{130}$ is either absent, $\mathrm{SnO}_{2}$-based, or $\mathrm{ZnO}$-based, and the $\mathrm{e}^{131}$ $\mathrm{CdS}$ layer is either absent, sputtered oxygenated $\mathrm{CdS},{ }^{132}$ or sublimated CdS. Commercial low-iron soda-lime ${ }^{133}$ glass coated with $10-\Omega / \square \mathrm{SnO}_{2}: \mathrm{F}$ TCO ("R10H1"134 manufactured by PPG Industries, Inc.) was the base- $-{ }^{135}$ line substrate for the $\mathrm{SnO}_{2}$-based HRT layers stud- ${ }^{136}$ ied here. $\mathrm{SnO}_{2}$-based HRT layers were deposited ${ }^{137}$ on FTO using atmospheric pressure chemical vapor deposition (APCVD) in a laboratory reactor, which simulates the in-line manufacturing process. ${\mathrm{All} \mathrm{SnO}_{2}-}^{-}$ based HRT layers deposited by PPG Industries had tin as a minimum of 80 at $\%$ of cations. Radio-frequency sputter-deposited $\mathrm{ZnO}$-based layers were deposited on TEC 10 (manufactured by Nippon Sheet Glass Co., Ltd.), a similar FTO-coated soda-lime glass product. For these layers a $10-\mathrm{cm}$ diameter target was used with a power of $180 \mathrm{~W}$, frequency of $13.56 \mathrm{MHz}$, a pressure of 5 mTorr, $1 \% \mathrm{O}_{2}$ in argon, and a targetsubstrate distance of $15 \mathrm{~cm}$. Targets were $99.99 \%$ pure, hot-pressed, mixed-powder targets (Plasmaterials, Inc.) with a 99.999\% pure $\mathrm{ZnO}$ target (Kurt J. Lesker) used for comparison.

Complete thin-film CdTe solar cells were prepared in the CSU Advanced Research Deposition System (ARDS). This system was used for sublimated $\mathrm{CdS}$, $\mathrm{CdTe}, \mathrm{CdCl}_{2}$ and $\mathrm{Cu}$ process steps. Cell fabrication and oxygenated $\mathrm{CdS}$ procedures have been described in detail [4]. Solar cell efficiency measurements were performed using a xenon arc lamp with AM1.5 filter; short-circuit current density was calibrated to cells measured by NREL.

Band measurements were performed using a PHI 5800 X-ray Photoelectron Spectroscopy system with a PREVAC UVS40A2 UV source. Samples were cleaned and heated in the ARDS to approximate the condition of the surface prior to semiconductor deposition, removed from the ARDS under an inert environment, and prepared in a glovebox under argon. 
Air exposure of the samples was less than $10 \mathrm{sec}_{-168}$ onds during loading into the XPS system to limit at-169 mospheric contamination of the surface. Measure -70 ments had a take-off angle of $85^{\circ}$ and a sample bias of 171 $-5 \mathrm{~V}$. Analysis followed the procedure of Helander ${ }_{172}$ et al. [18]. Synchrotron-based measurements were 173 performed on beamline X1B at the National Syn -174 chrotron Light Source at Brookhaven National Lab-175 oratory. A beam energy of $550 \mathrm{eV}$ was used for $\mathrm{XES}_{176}$ which corresponds to an attenuation length in $\mathrm{SnO}_{2177}$ of $80 \mathrm{~nm}$ [19]. A range of approximately 522-554178 eV was scanned to obtain the O-K-edge XAS. 179

\section{Results}

\section{1. $\mathrm{SnO}_{2}$-based HRT layers}

Many candidate $\mathrm{SnO}_{2}$-based HRT layers were tested in devices with various alloying elements, alloy com- ${ }^{184}$ positions, and thicknesses. Alloying elements tested ${ }^{185}$ were $\mathrm{Zn}, \mathrm{Ga}$, In, and $\mathrm{N}$ as well as un-alloyed tin ox- ${ }^{186}$ ide in the thickness range of $80-250 \mathrm{~nm}$. These layers ${ }^{187}$ were screened to test quickly which were most ef- ${ }^{188}$ fective. A preliminary experiment was devised with ${ }^{189}$ one substrate each of thick $(>120 \mathrm{~nm})$ and thin $\left(<<^{190}\right.$ $90 \mathrm{~nm}$ ) sublimated $\mathrm{CdS}$ using both the TCO/HRT/ ${ }^{191}$ $\mathrm{CdS} / \mathrm{CdTe}$ and $\mathrm{TCO} / \mathrm{CdS} / \mathrm{CdTe}$ structures. The dif- ${ }^{192}$ ference between voltage and fill factor of these devices with and without HRT was statistically tested ${ }^{194}$ to determine if an HRT effect was significant. The best-performing $\mathrm{SnO}_{2}$-based HRT layer was found ${ }^{196}$ to be a dilute (2-3 at\%) zinc-doped tin oxide using monobutyl tin trichloride and diethyl zinc as precur- sors; an HRT thickness of $150 \mathrm{~nm}$ was found to be optimal. This HRT layer was used in subsequent experiments in which the sublimated CdS layer thickness was varied.

Devices with the structure TCO/HRT/sublimated $\mathrm{CdS} / \mathrm{CdTe}$ were made using the $\mathrm{SnO}_{2}: \mathrm{Zn} \mathrm{HRT}$, and devices with the structure TCO/sublimated CdS/CdTe served as a control (see Figure 1). Device quality had little dependence on CdS layer thickness above a critical value of about $90 \mathrm{~nm}$ for devices without HRT and $60 \mathrm{~nm}$ for devices with HRT. Below this value, $\mathrm{V}_{O C}$ gradually declined with a minimum at $0 \mathrm{~nm}$ (a device with no CdS layer). Meanwhile, current continuously improved with thinner CdS. Devices with the HRT showed both a lower critical thickness and a higher $\mathrm{V}_{O C}$ with $0 \mathrm{~nm}$ of $\mathrm{CdS}$. For all values of $\mathrm{CdS}$ thickness, devices typically exhibited high shunt resistance. The best devices with the structures $\mathrm{TCO} /$ CdTe, TCO/HRT/CdTe, TCO/CdS/CdTe, and TCO/ HRT/CdS/CdTe are shown in Figure 2. With a CdS layer, the increased current with HRT was a greater effect than the slightly reduced voltage, highlighting the importance of short-circuit current gains as the benefit of the HRT layer.

CdTe devices often show light-dark crossover that increases as $\mathrm{CdS}$ thickness decreases. Some devices with the structure $\mathrm{TCO} / \mathrm{CdTe}$ (without any HRT or CdS layer) exhibit strong light-dark crossover, in which even low illumination levels cause a large drop in series resistance compared to the dark measurement. This behavior was examined by illuminating the de- 
vices with red and blue light-emitting diodes and varyzso ing the supply current by several orders of magni- ${ }_{231}$ tude; both the LED current and the short-circuit cur- ${ }_{232}$ rent were measured, and remained linearly related ${ }_{233}$ over the measurement range. Figure $3 \mathrm{a}$ illustrates ${ }_{234}$ the drastic change in series resistance as LED inten- ${ }_{235}$ sity is varied over several orders of magnitude, cor- $^{-}{ }_{236}$ responding with a change in photocurrent. Figure $3 b_{237}$ illustrates this phenomenon in parametric form for $_{238}$ both blue and red LED illumination. The relation- ${ }_{239}$ ship between $\mathrm{J}_{S C}$ and series resistance for this device ${ }_{240}$ is comparable when red and blue LEDs are used. The $\mathrm{T}_{241}$ presence of light greatly reduces the barrier to for- ${ }_{242}$ ward electron current. This change is opposite in $\mathrm{di}_{243}$ rection and much larger in magnitude than the pho- $_{244}$ tocurrent, indicating that low levels of photogener- ${ }_{245}$ ated carriers can modify the junction behavior. For $_{246}$ devices that do have $\mathrm{CdS}$, this light-dark crossover $_{247}$ can be due to photoconductivity in the $\mathrm{CdS}$, which ${ }_{248}$ occurs when blue light is present [20]. Here, no $\mathrm{CdS}_{249}$ layer is present, and the series resistance of the diode $e_{250}$ in forward bias is a function of the light absorbed ${ }_{251}$ in the CdTe regardless of whether red or blue light ${ }_{252}$ is used. Therefore, the light appears to be filling ${ }_{253}$ charged states at the $\mathrm{TCO} / \mathrm{CdTe}$ interface rather $\operatorname{than}_{254}$ in any CdS layer. Negatively charged interface $\mathrm{de}_{-255}$ fects have a similar band alignment effect as a con- ${ }_{256}$ tacting material with high electron affinity, and these ${ }_{257}$ two properties have additive effects. For a variety of ${ }_{258}$ front contacts, higher $\mathrm{V}_{O C}$ is correlated with reduced ${ }_{259}$ light-dark crossover.

\subsection{ZnO-based HRT layers}

$\mathrm{ZnO}$ has been used as an effective HRT. When CdTe is deposited directly on sputtered $\mathrm{ZnO}, \mathrm{V}_{O C}$ of $500-600 \mathrm{mV}$ or more is produced. Band alignment measurements by $\mathrm{Rao}$ et al. indicate that $\mathrm{ZnO}$ has a larger electron affinity than $\mathrm{CdS}$; alloying with $\mathrm{MgO}$ to produce $\mathrm{Mg}_{x} \mathrm{Zn}_{1-x} \mathrm{O}$ (MZO) with a composition of $x=0.15$ can reduce the electron affinity and produce a flatter conduction band alignment with $\mathrm{CdS}$ [21]. In $\mathrm{Cu}(\mathrm{In}, \mathrm{Ga}) \mathrm{Se}_{2}$ thin-film solar cells, this alloy has been shown to have superior performance as a replacement for $\mathrm{ZnO}$ in the front contact [22]. $\mathrm{Mg}_{x} \mathrm{Zn}_{1-x} \mathrm{O}$ has the added benefit of increasing the optical bandgap of the layer for better ultraviolet light transmission [23]. Varying the magnesium content from $x=0$ to $x=0.30$ allowed Erfurth et al. to tune the conduction band offset (CBO) between a "cliff," or negative CBO, and a "spike," or positive CBO, with both open-circuit voltage and fill factor improving with magnesium addition [24].

Over the range $x=0$ to $x=0.24$, the films remain in the wurtzite crystal structure with the lattice constant $c$ reducing from $0.5211 \mathrm{~nm}$ to $0.5155 \mathrm{~nm}$ for films deposited on glass at $300{ }^{\circ} \mathrm{C}[25]$; the lattice constant $c$ for wurtzite $\mathrm{CdS}$ is $0.6756 \mathrm{~nm}$. This trend also extends to the lattice constant $a$ in the closepacking direction, which is more relevant for $\mathrm{CdTe}$ growth. The constant $a$ is smaller for $\mathrm{CdS}$ than for CdTe, so further decreasing this parameter would increase lattice mismatch. If lattice mismatch with $\mathrm{CdTe}$ were a decisive factor in the quality of this polycrys- 
talline interface, $\mathrm{Mg}_{x} \mathrm{Zn}_{1-x} \mathrm{O}$ would produce diodese92 with the poorest performance.

In this work $\mathrm{Mg}_{x} \mathrm{Zn}_{1-x} \mathrm{O}$ was examined in de-294 vices with no CdS layer in the structure TCO/Mg $\mathrm{Zn}_{\mathrm{pag}_{x}}$ Oxwhen deposited on a TCO layer would additionally CdTe, deposited by RF sputter deposition using tar-296 get compositions of $x=0.15,0.20$, and $0.25\left(\mathrm{MgO}_{297}\right.$ weight percentages of 8,11 , and $14 \%$ with the re-298 mainder $\mathrm{ZnO})$. Pure $\mathrm{ZnO}$ was also tested as a com-299 parison. Films made from these targets exhibited ${ }_{300}$ the expected increase in optical bandgap relative to801 $\mathrm{ZnO}$; measurements by XPS of the film made fromвo2 the $11 \mathrm{wt} \%$ target show the magnesium content $x_{303}$ is slightly higher in the film $(x=0.23)$ than in the 304 target $(x=0.20)$ in agreement with Hariskos et al.305 [22]. At each composition, a thicker film with mea-306 sured thickness near $500 \mathrm{~nm}$ was deposited on un-307 coated glass for optical measurements. In Figure $4_{308}$ the transmission is shown over a wide wavelength ${ }^{\circ} 09$ range along with the optical bandgap calculated from ${ }^{10}$ Tauc plots of the data. The films are transparent 11 from their bandgap in the range of $350-400 \mathrm{~nm}$ out tos12 long wavelengths up to $2 \mu \mathrm{m}$. The Tauc plot shows 313 that bandgap increases, as expected, with increasing $g_{314}$ magnesium composition.

$\mathrm{Mg}_{x} \mathrm{Zn}_{1-x} \mathrm{O}$ films approximately $1 \mu \mathrm{m}$ thick at ${ }_{316}$ each magnesium concentration were deposited on low alkali Eagle XG glass (Corning Inc.) in order to limit ${ }_{31}$ the potential electronic effects of sodium diffusion. ${ }_{.319}$ Small, 1-cm square samples were prepared with sol-з20 dered indium contacts as corner electrodes, and Hall ${ }_{21}$ measurements were attempted using an Ecopia $\mathrm{HMS}_{322}$
3000 using the van der Pauw method. The samples were too resistive to measure, implying a resistivity of $10^{7} \Omega$-cm or greater. The resistivity of the film depend on the band alignment in the structure.

Layers from 25-400 $\mathrm{nm}$ thick were deposited on FTO-coated glass and devices were subsequently fabricated, using no CdS layer (shown in Figure 5). The device with a $\mathrm{ZnO}$ layer has low $\mathrm{V}_{O C}$ which is attributed to a flat or slightly negative $\mathrm{CBO}$ in combination with interface defects. The $8 \mathrm{wt} \%$ sample has high $\mathrm{V}_{O C}$ and fill factor. Almost all the devices with thickness above $50 \mathrm{~nm}$ show excellent $\mathrm{V}_{\text {OC }}$ near 850 $\mathrm{mV}$; however, thinner layers show reduced $\mathrm{V}_{O C}$, an effect that becomes stronger with lower magnesium content. The $\mathrm{Mg}_{x} \mathrm{Zn}_{1-x} \mathrm{O}$ layers with higher magnesium exhibit a strong secondary barrier in the $\mathrm{J}-\mathrm{V}$ curve with $100 \mathrm{~nm}$ or greater thickness. At the optimal point of $50 \mathrm{~nm}$, made with the $11 \mathrm{wt} \% \mathrm{MgO}$ target, numerous devices with efficiency values of over $15 \%$ have been fabricated with no CdS-based layer, and no antireflection layer. This demonstrates use of a thin, resistive oxide layer which replaces both as HRT and CdS layers when composition and thickness of the layer are preliminarily optimized. The $\mathrm{J}-\mathrm{V}$ curves of devices with $100-\mathrm{nm}$ thick $\mathrm{Mg}_{x} \mathrm{Zn}_{1-x} \mathrm{O}$ layers of each composition are shown in Figure 6. The $11 \mathrm{wt} \%$ and $14 \mathrm{wt} \%$ samples have high $\mathrm{V}_{O C}$ and a secondary barrier (kink) in the $\mathrm{J}-\mathrm{V}$ curve, attributed to a positive CBO. The $11 \mathrm{wt} \%$ has a larger kink, which is likely due to process variability; in 
general, small changes in $\mathrm{J}-\mathrm{V}$ behavior are observed ${ }_{354}$ with target break-in. There is a clear interaction be-355 tween thickness and composition in determining $\mathrm{V}_{O C^{356}}$ and barrier behavior that can be used to reach an op-357 timum.

In the context of $\mathrm{CdTe}$ devices there are many359 similarities between $\mathrm{Mg}_{x} \mathrm{Zn}_{1-x} \mathrm{O}$, and sputtered, oxy-360 genated CdS that was explored in previous work [4] $]_{361}$ Relative to sublimated $\mathrm{CdS}$, oxygenated $\mathrm{CdS}$ has $\mathrm{a}_{62}$ lower carrier concentration, and can be tuned to have 363 a larger bandgap and lower electron affinity. Like 364 oxygenated $\mathrm{CdS}, \mathrm{Mg}_{x} \mathrm{Zn}_{1-x} \mathrm{O}$ also has a very low car-365 rier concentration. Relative to $\mathrm{ZnO}, \mathrm{Mg}_{x} \mathrm{Zn}_{1-x} \mathrm{O}$ ha\$s66 a higher bandgap and lower electron affinity. In de-367 vices, an increase in oxygen content in oxygenated 668 $\mathrm{CdS}$ can produce higher current and voltage, but causes a secondary barrier (kink) to appear. $\mathrm{Mg}_{x} \mathrm{Zn}_{1-x} \mathrm{O}$ lay-370 ers that are thicker and contain more $\mathrm{Mg}$ also tend $\mathrm{d}_{71}$ to exhibit higher secondary barriers in devices. This372 phenomenon has been previously explained by 1 -dimen device modeling in which the electron affinity of the $e_{34}$ CdS layer was decreased and a secondary barrier wa\$75 produced.

\subsection{Band Measurements of HRT layers}

A subset of all the $\mathrm{SnO}_{2}$-based HRT layers tested were chosen with a variety of alloying element and concentration, with a standard thickness of $150 \mathrm{~nm}$ if available. The $\mathrm{ZnO}$ and $11 \mathrm{wt} \% \mathrm{Mg}_{x} \mathrm{Zn}_{1-x} \mathrm{O}$ were also measured using the best-performing thickness of $50 \mathrm{~nm}$ deposited on TEC 10. Three sets of devices and band measurements were made with this set of
HRT layers. The first set was made without any CdS layer. A second set of devices was made with a 50 nm oxygenated CdS layer, and a third set used 50 nm sublimated CdS. The selected subset of HRT layers was measured by UPS. These measurements are summarized in Table 1. The work function and Fermi level were measured, and electron affinity was calculated as a way to estimate band alignment. For each combination of parameters, a substrate with nine devices was prepared with a device area of $0.7 \mathrm{~cm}^{2}$. The sputtered, oxygenated CdS has very low freeelectron concentration which was measured at approximately $10^{12} \mathrm{~cm}^{-3}$ using Hall measurements after annealing to process temperatures of $500^{\circ} \mathrm{C}$. Figure 7a shows that for devices without $\mathrm{CdS}$, electron affinity is a strong predictor of $\mathrm{V}_{O C}$ (as well as efficiency). For devices with $50 \mathrm{~nm}$ of oxygenated $\mathrm{CdS}$ in between the HRT and CdTe (Figure 7b), the dependence becomes weaker. The dependence is weaker istinlalfor devices with sublimated CdS (Figure 7c).

The fluorine-doped tin oxide TCO and optimal $\mathrm{SnO}_{2}: \mathrm{Zn}$ HRT were characterized via X-ray emission spectroscopy and x-ray absorption spectroscopy at a photon energy of $550 \mathrm{eV}$ using a synchrotron beamline. These techniques do not require emission of a photoelectron and therefore probe more deeply than XPS and UPS, with an attenuation length of approximately $80 \mathrm{~nm}$. This makes the measurements insensitive to surface contamination which is typically less than $1 \mathrm{~nm}$ but can strongly affect surface-sensitive band measurements for some materials. This sup- 
ports photoelectron spectroscopy band measurement \$ $_{16}$ and indicates they are not due to an interaction with w17 $_{47}$ adventitious materials. X-ray absorption spectroscopy/8 probes the unoccupied states of the material; the grounding current of the sample is measured to determine 420 the extent of absorption. X-ray emission spectroscopyzi measures the energy of X-rays that are emitted when 22 electrons fall from valence states to core holes cre-423 ated by incident radiation. These techniques show 424 that both the valence and conduction bands shift away 425 from core states in the HRT versus the TCO, indicat-426 ing that the HRT has a lower electron affinity, as seen ${ }_{42}$ in Figure 8.

\subsection{1-D modeling of HRT layer band alignment}

Modeling of 1-dimensional structures was conducted in the SCAPS software [26]. This model is a simplification of the actual cell and ignores phenomena related to polycrystallinity. Some properties of the baseline cell are shown in Table 2; parameters not directly related to the front contact were mostly taken from Ref. [27] and other parameters were varied to perform the study. The absorber lifetimes were set to $2 \mathrm{~ns}$ for both holes and electrons. The layer thickness values were set to match experimental samples. The first set of models explores the effect of HRT electron affinity when no $\mathrm{CdS}$ is present. The light dependence of the $\mathrm{TCO} / \mathrm{CdTe}$ diodes with no $\mathrm{CdS}$ as shown in Figure 3 implies the presence of charged defects at the CdTe/oxide interface. The oxide/CdTe interfaces are also likely to have high surface recombination velocity due to poor lattice matching. To model these effects, acceptor-like interface defects were placed at the $\mathrm{SnO}_{2} / \mathrm{CdTe}$ interface in the middle of the CdTe bandgap with a density of $2 \cdot 10^{1} 2 \mathrm{~cm}^{-2}$, and interface recombination velocity was set to $10^{7}$ $\mathrm{cm} / \mathrm{s}$.

The experimental results for devices with no CdS suggest that a higher electron affinity should result in a reduced open-circuit voltage of the cell. The effect of the modeled band structure on model J-V behavior can be seen in Figure 9. The results in figure $9 \mathrm{~b}$ correspond with the curves in Figure 6 and $7 \mathrm{a}$. Varying the oxide electron affinity in the model produces a similar variation in $\mathrm{J}-\mathrm{V}$ characteristics. As the $\mathrm{CBO}$ becomes flat or a cliff, there is both a decreasing device voltage and fill factor and an increasing loss of current due to interface recombination. In real devices, this loss would depend not only on band alignment but the defect concentration and carrier concentration for the specific oxide. When the electron affinity of the oxide is reduced to $4.0 \mathrm{eV}$, a kink appears in the current density-voltage curve, as with high-magnesium MZO layers in Figure 6. Based on the band alignment measurements, $\mathrm{SnO}_{2}$-based oxides have band alignments from flat to a $0.9 \mathrm{eV}$ cliff. For $\mathrm{ZnO}$-based HRT layers, the $\mathrm{ZnO}$ appears to have a nearly flat conduction band offset. The optimized MZO layer has a spike in the conduction band of about $0.3 \mathrm{eV}$ at the interface. Experimental $\mathrm{V}_{O C}$ results from Figure 7 are compared to model results in Figure 10a.

When $50 \mathrm{~nm}$ of $\mathrm{CdS}$ or oxygenated $\mathrm{CdS}$ is present, 
the lowest experimental open-circuit voltages are ap-477 proximately $600 \mathrm{mV}$, and the slope of the lines $i_{478}$ Figure $7 \mathrm{~b}$ and $\mathrm{c}$ is reduced. A large barrier to elec-479 tron injection would be expected at the oxide/CdS $\mathrm{S}_{40}$ interface for oxides with high electron affinity, but ${ }_{81}$ this is not seen in actual devices; the oxide/CdS in-482 terface is also likely much different than the various483 oxide/CdTe interfaces. The band alignment of this $\$ 84$ interface is pinned in a relatively narrow range due 485 to defects in $\mathrm{CdS}$ as discussed by Klein [3]. A $50 \mathrm{~nm}_{486}$ layer of $\mathrm{CdS}$ was added to the model to form an $\mathrm{OX}^{-487}$ ide/CdS/CdTe structure. This CdS layer has donor ${ }_{-488}$ like defects placed $0.5 \mathrm{eV}$ below the conduction band ${ }_{48}$ minimum. Figure $10 \mathrm{~b}$ compares experimental and490 model $\mathrm{V}_{O C}$ results with modeled CdS. With the $\mathrm{CdS}_{491}$ layer present, the device parameters are insensitive to492 small negative or positive CBO's. As electron affin-493 ity is increased above $4.6 \mathrm{eV}$, the device voltage is reduced. For larger oxide electron affinities a barrier appears in the model $\mathrm{J}-\mathrm{V}$ curves that is never ob- ${ }^{495}$ served in experimental devices with CdS; also, if the ${ }^{496}$ oxide electron affinity is $4.0 \mathrm{eV}$ or lower an unphys- ${ }^{497}$ ical barrier appears. Therefore, this interface may be $\mathrm{e}^{498}$ pinned within a more narrow range.

\section{Discussion}

The key to understanding the role of each layer in the front contact structure is noting the difference between the TCO/CdTe, TCO/HRT/CdTe, TCO/CdS/ CdTe, and TCO/HRT/CdS/CdTe devices. Differences in carrier concentration or resistivity of the material (which has been widely discussed), the existence of pinholes and other morphological imperfections, their crystallographic mismatch, and band alignment with CdTe all affect recombination at the junction.

The common theory states that pinholes where there is no $\mathrm{CdS}$ cause weak diodes which shunt current away from stronger $\mathrm{CdS} / \mathrm{CdTe}$ diodes. This was not justified by experimental evidence since cells have not shown increasing pinhole density or area with thinner CdS layers. Furthermore, pinholes do not seem to have as large an effect on device efficiency as a simple parallel diode model (allowing for unlimited forward current densities) suggests [16]. This theory also fails to explain why devices without $\mathrm{CdS}$ are typically of poor quality and the dependence of device parameters on thickness is independent of whether pinholes exist.

\subsection{Lattice Mismatch}

One theory that holds true for single crystal, epitaxially-grown devices is that the lattice constant between the absorber and underlying material must match closely in order to provide a good growth template, which will minimize defects in the material. In single crystals, strain due to mismatch is relieved by the creation of threading dislocations which continue through the entire thickness of the material. To reduce interface recombination, a good crystallographic match is considered important to reduce the interface defect density, and to provide a growth template which minimizes defects in the CdTe bulk. CdS has a lattice mismatch of $10 \%$ with CdTe, and only inter- 
diffuses slightly during high-temperature device pro-539 cessing [28]. Since $\mathrm{Mg}_{x} \mathrm{Zn}_{1-x} \mathrm{O}$ has the same crys-540 tal structure and a lower lattice constant than both b $_{54}$ $\mathrm{ZnO}$ and $\mathrm{CdS}$, it possesses greater mismatch to $\mathrm{CdTe}_{42}$ and would not produce a high-quality device if lattices 53 matching were a paramount consideration. In poly-544 crystalline materials, there is already a relatively high $h_{54}$ concentration of interface defects, and strain can bes46 relieved at grain boundaries, terminating dislocation ${ }_{547}$ Therefore, rules that are predictive in single-crystab 48 epitaxial devices may not apply equally well to these 549 less ideal materials. Still, improving the quality of 550 this interface may prove important to voltage increasess above the current state of the art. Adding a patterned ${ }_{552}$ insulating oxide with nanoscale $\mathrm{CdS}$ contacts is one $\mathrm{e}_{53}$ way of creating single-crystal CdTe islands, and may554 improve growth of the CdTe by preventing disloca-555 tions and other defects in the CdTe absorber $[29,30]_{556}$

\subsection{Band alignment of CdTe front contacts}

The ideal front contact of the heterojunction will maximize the built-in potential by holding the Fermi level near the conduction band minimum of $\mathrm{CdTe}_{56}$ in equilibrium and minimize interface recombination at the front CdTe interface. To achieve this, a flat or slightly positive CBO (spike) is desirable, and a negative CBO (cliff) would lead to reduced built-in potential and greater interface recombination; here, cliff and spike are defined as in Figure 1 of Klenk [31]. The front contact structure also serves to provide a low-resistance contact for electrons; therefore, the positive conduction band offset must be small or else a secondary barrier (kink) will appear in the current-voltage curve of the cell. The electron affinity of the HRT, including any effects of interface charge, is a key predictor of HRT performance. Negatively charged acceptor defects at the interface have a similar effect to a high electron affinity contact material, and these defects would change dependent on the specific combination of materials at the interface. These defects do not appear to dominate the interfaces in question, but could be a cause of scatter in the data.

Commonly used values for the tin oxide electron affinity indicate that this layer has a relatively flat conduction band alignment with CdTe [27]. The band alignment of the $\mathrm{SnO}_{2} / \mathrm{CdS}$ interface has been investigated both by progressive growth of $\mathrm{CdS}$ [32] and by sputter depth profiling [33]. It was reported that the offset at this interface was $\Delta \mathrm{E}_{C}=-0.1 \mathrm{eV}$. This was measured after the full thickness of $\mathrm{CdS}$ was deposited and not immediately at the interface. The authors observed the Fermi level to be well below the conduction band in the CdS with band bending away from the interface, resulting in a total barrier height of $0.4 \mathrm{eV}$. An earlier study by Niles et al. reported a flat conduction band at the interface [34] However, recent studies specifically of fluorine-doped tin oxide report a work function of $5 \mathrm{eV}$ [35], much higher than commonly used for $\mathrm{SnO}_{2}$ in CdTe device modeling; if true, then a CdTe heterojunction with FTO or a device with thin $\mathrm{CdS}$ would create a cliff alignment. Klein reports that there is a wide 
variation of more than $1 \mathrm{eV}$ in the work function of $f_{601}$ $\mathrm{SnO}_{2}$, which cannot be accounted for by a difference $e_{62}$ in doping [36]. Furthermore, because FTO is de-603 generately doped, the Fermi level is reported to bes04 up to $0.6 \mathrm{eV}$ above the conduction band minimumbo5 [35]. With Fermi level pinning at the CdTe conduc-606 tion band minimum, this would in itself create a cliff607 band alignment at the front interface. It appears thatoos the work function and electron affinity of tin oxidesog with different dopants and alloy materials is highly610 variable, and a single value cannot account for alk11 processing variables.

As a wide-bandgap, n-type semiconductor, FTO $_{613}$ can be used directly as the front contact of the so-614 lar cell. As reported here and by others [9], a FTO/615 CdTe junction results in a cell with very low open- -16 circuit voltage, while a tin oxide-based HRT/CdTes17 junction produces an open-circuit voltage intermedi-618 ate to $\mathrm{FTO} / \mathrm{CdTe}$ and $\mathrm{CdS} / \mathrm{CdTe}$ junctions. None of 19 these devices necessarily has low shunt resistance. 620

Crossover of the light and dark curves is a common phenomenon seen in thin-film solar cells. This ${ }^{621}$ has been explained as a conduction band "spike" between the absorber and CdS that is slightly reduced due to photoconductivity in the CdS layer [20]. Without any $\mathrm{CdS}$ layer, charged defects at the $\mathrm{TCO} / \mathrm{CdTe}_{625}$ interface rather than charged defects in the $\mathrm{CdS}$ can $_{626}$ explain the light-dependent effect and would cause unfavorable band alignment. An effect similar to that of an HRT has been demonstrated simply by plasma treatment of the TCO, which affects at most a few tens of nanometers of the surface [37], further indicating that interface charge is in part responsible for unfavorable band alignment.

The $\mathrm{SnO}_{2}: \mathrm{F} / \mathrm{CdTe}$ band alignment is far from ideal, and device results here indicate that some HRT materials which increase the resistivity of this material but do not change the electron affinity appreciably, such as the nitrogen-doped $\mathrm{SnO}_{2}: \mathrm{F}$, produce no improvement in cell performance. Materials that have lower electron affinity produce the desired HRT effect. The $\mathrm{ZnO}-\mathrm{MgO}$ alloys provide a model system for testing the effects of electron affinity, since $\mathrm{ZnO}$ is known to perform moderately well as an HRT layer, and adding magnesium changes the electron affinity of this layer without significant changes to the crystalline structure, resistivity, or deposition process. Improved device performance with the elimination of CdS was demonstrated, and both cliff and spike behavior could be demonstrated by varying thickness and composition of the $\mathrm{Mg}_{x} \mathrm{Zn}_{1-x} \mathrm{O}$ layer.

\section{Conclusions}

Pinholes do not seem to be the primary cause of effects seen relative to CdS layer thickness. The existence of a wurtzite $\mathrm{Mg}_{x} \mathrm{Zn}_{1-x} \mathrm{O}$ layer that can produce a high open-circuit voltage without $\mathrm{CdS}$, but has a larger lattice mismatch with CdTe relative to $\mathrm{CdS}$ or $\mathrm{ZnO}$, implies also that lattice matching is not the key factor for producing an effective front contact to CdTe. In contrast, band alignment considerations have consistently predicted the performance of front 
contact layers, including with sputtered, oxygenated 659

CdS layers [4].

While sparsely explored in the CdTe literature, the importance of band alignment at the front contact has been well explored and confirmed in $\mathrm{Cu}(\mathrm{In}, \mathrm{Ga}) \mathrm{Se}_{2}$ thin-film solar cells, such as with $\mathrm{Mg}_{x} \mathrm{Zn}_{1-x} \mathrm{O}$ layers. The weakness of the TCO/CdTe diode appears to derive from unfavorable band alignment of the TCO layer with $\mathrm{CdTe}$, from a combination of electron affinity, charged defects, and degenerate doping. This causes a strong, light-sensitive barrier to form in addition to the poor device properties of $\mathrm{TCO} / \mathrm{CdTe}$ junctions. HRT layers, which are not degenerately doped, can have a wide range of effectiveness in improving contact properties. The $\mathrm{SnO}_{2}$-based HRT layers shown here have a wide range of effectiveness which correlates with electron affinity. In the case of very poor band alignment between oxide and CdTe, $\mathrm{CdS}$-based layers that are very thin or have low carrier concentration do not produce high-efficiency devices; however, a thin, resistive 50-nm layer of $\mathrm{Mg}_{x} \mathrm{Zn}_{1-x}$ References with optimized band alignment can replace both the HRT and CdS layers. In short, band alignment concerns appear to explain interface phenomena where other variables such as fractional pinhole area and lattice mismatch do not, and account for the inconsistent behavior of HRT materials with high resistivity.

\section{Acknowledgements}

Use of the National Synchrotron Light Source at Brookhaven National Laboratory is supported by the U. S. Department of Energy, Office of Science, Office of Basic Energy Sciences, under Contract DEAC02-98CH10886. The authors would like to thank Kevin Smith and David Newby for use of the endstation of Beamline X1B and Jake Bowers of Loughborough University for preliminary $\mathrm{ZnO}$ samples. John Williams and James Sites helped with editing the manuscript. Alamgir would like to thank PPG Industries for financial support for conducting synchrotron-based experiments. This work was supported by the Department of Energy Supply Chain program (DE-EE000 4736). Oxygenated CdS research was supported by the National Science Foundation Accelerating Innovation Research (AIR) program (IIP-1127362) and the Department of Energy F-PACE program (DE-EE000 5399).

[1] First solar achieves efficiency, durability milestones, http://investor.firstsolar.com/releasedetail. cfm?ReleaseID=895118 (Feb. 2015).

[2] M. Topič, R. Geisthardt, J. Sites, Performance limits and status of single-junction solar cells with emphasis on CIGS, IEEE J. Photovoltaics 5 (1) (2015) 360-365. doi:10.1109/JPHOTOV.2014.2359135.

[3] A. Klein, Energy band alignment in chalcogenide thin film solar cells from photoelectron spectroscopy, Journal of Physics: Condensed Matter 27 (13) (2015) 134201. doi:10.1088/0953-8984/27/13/134201. 
[4] J. M. Kephart, R. M. Geisthardt, W. S. Sampath, Optimization of CdTe thin-film solar cell efficiency using a sputtered, oxygenated CdS window layer, Prog. Photovoltaics Res. Appl.doi:10.1002/pip.2578.

[5] J. Fritsche, A. Klein, W. Jägermann, Thin film solar cells: Materials science at interfaces, Adv. Eng. Mater. 7 (10) (2005) 914-920. doi:10.1002/adem.200500126.

[6] X. Wu, J. C. Keane, R. G. Dhere, C. DeHart, D. S. Albin, A. Duda, T. A. Gessert, S. Asher, D. H. Levi, P. Sheldon, $16.5 \%$-efficient $\mathrm{CdS} / \mathrm{CdTe}$ polycrystalline thin-film solar cell, in: Proc. of the 17th European Photovoltaic Solar Energy Conference, Munich, Germany, 2001, pp. 9951000.

[7] A. D. Compaan, A. Gupta, J. Drayton, S.-H. Lee, S. Wang, 14\% sputtered thin-film solar cells based on CdTe, Phys. Status Solidi B 241 (3) (2004) 779-782. doi:10.1002/pssb.200304281.

[8] J. D. Major, Y. Y. Proskuryakov, K. Durose, Impact of CdTe surface composition on doping and device performance in close Space sublimation deposited CdTe solar cells, Prog. Photovoltaics Res. Appl. 21 (4) (2011) 436443. doi:10.1002/pip.1196.

[9] B. E. McCandless, K. D. Dobson, Processing options for CdTe thin film solar cells, Sol. Energy 77 (6) (2004) 839_ 856. doi:10.1016/j.solener.2004.04.012.

[10] T. Takamoto, T. Agui, H. Kurita, M. Ohmori, Improved junction formation procedure for low temperature deposited CdS/CdTe solar cells, Sol. Energy Mater. Sol. Cells 49 (14) (1997) 219-225. doi:10.1016/S09270248(97)00198-0.

[11] D. H. Rose, F. S. Hasoon, R. G. Dhere, D. S. Albin, R. M. Ribelin, X. S. Li, Y. Mahathongdy, T. A. Gessert, P. Sheldon, Fabrication procedures and process sensitivities for CdS/CdTe solar cells, Prog. Photovoltaics Res. Appl. 7 (5) (1999) 331-340. doi:10.1002/(SICI)1099159X(199909/10)7:5¡331::AID-PIP257;3.0.CO;2-P.

[12] X. Li, R. Ribelin, Y. Mahathongdy, D. Albin, R. Dhere, D. Rose, S. Asher, H. Moutinho, P. Sheldon, The effect of high-resistance $\mathrm{SnO}_{2}$ on $\mathrm{CdS} / \mathrm{CdTe}$ device performance, in: AIP Conference Proceedings, Vol. 462, 1999, pp. 230235. doi:10.1063/1.57900.

[13] C. S. Ferekides, R. Mamazza, U. Balasubramanian, D. L. Morel, Transparent conductors and buffer layers for CdTe solar cells, Thin Solid Films 480 (2005) 224-229. doi:10.1016/j.tsf.2004.11.094.

[14] X. Wu, S. Asher, D. H. Levi, D. E. King, Y. Yan, T. A. Gessert, P. Sheldon, Interdiffusion of $\mathrm{CdS}$ and $\mathrm{Zn}_{2} \mathrm{SnO}_{4}$ layers and its application in $\mathrm{CdS} / \mathrm{CdTe}$ polycrystalline thin-film solar cells, J. Appl. Phys. 89 (8) (2001) 45644569. doi:10.1063/1.1351539.

[15] M. Tashkandi, W. Sampath, Eliminating pinholes in CSS deposited CdS films, in: 38th Photovoltaic Specialists Conference, IEEE, Austin, TX, 2012, pp. 143-146. doi:10.1109/PVSC.2012.6317587.

[16] J. M. Kephart, R. M. Geisthardt, Z. Ma, J. McCamy, W. S. Sampath, Reduction of window layer optical losses in $\mathrm{CdS} / \mathrm{CdTe}$ solar cells using a float-line manufacturable HRT layer, in: 39th Photovoltaic Specialists Conference, IEEE, Tampa,FL, 2013, pp. 1653-1657. doi:10.1109/PVSC.2013.6744462.

[17] B. Korevaar, A. Halverson, J. Cao, J. Choi, C. CollazoDavila, W. Huber, High efficiency CdTe cells using manufacturable window layers and CdTe thickness, Thin Solid Films 535 (2013) 229-232. doi:10.1016/j.tsf.2012.12.079.

[18] M. Helander, M. Greiner, Z. Wang, Z. Lu, Pitfalls in measuring work function using photoelectron spectroscopy, Appl. Surf. Sci. 256 (8) (2010) 2602-2605. doi:10.1016/j.apsusc.2009.11.002.

[19] B. L. Henke, E. M. Gullikson, J. C. Davis, X-Ray Interactions: Photoabsorption, Scattering, Transmission, and Reflection at $\mathrm{E}=50-30,000 \mathrm{eV}, \mathrm{Z}=1-92$, Atomic Data and Nuclear Data Tables 54 (2) (1993) 181-342. doi:10.1006/adnd.1993.1013.

[20] M. Gloeckler, C. R. Jenkins, J. R. Sites, Explanation of light/dark superposition failure in CIGS solar 
cells, in: Proc. Mat. Res. Soc. Symp., Vol. 763, 2003. doi:10.1557/PROC-763-B5.20.

[21] G. V. Rao, F. Säuberlich, A. Klein, Influence of Mg content on the band alignment at $\mathrm{CdS} /(\mathrm{Zn}, \mathrm{Mg}) \mathrm{O}$ interfaces, Appl. Phys. Lett. 87 (3) (2005) 032101-032101-3. doi:10.1063/1.1995951.

[22] D. Hariskos, B. Fuchs, R. Menner, N. Naghavi, C. Hubert, D. Lincot, M. Powalla, The $\mathrm{Zn}(\mathrm{S}, \mathrm{O}, \mathrm{OH}) / \mathrm{ZnMgO}$ buffer in thin-film $\mathrm{Cu}(\mathrm{In}, \mathrm{Ga})(\mathrm{Se}, \mathrm{S})_{2}$-based solar cells part II: Magnetron sputtering of the $\mathrm{ZnMgO}$ buffer layer for in-line co-evaporated $\mathrm{Cu}(\mathrm{In}, \mathrm{Ga}) \mathrm{Se}_{2}$ solar cells, Prog. Photovoltaics Res. Appl. 17 (7) (2009) 479-488. doi:10.1002/pip.897.

[23] T. Minemoto, T. Negami, S. Nishiwaki, H. Takakura, Y. Hamakawa, Preparation of $\mathrm{Zn}_{1-x} \mathrm{Mg}_{x} \mathrm{O}$ films by radio frequency magnetron sputtering, Thin Solid Films 372 (12) (2000) 173-176. doi:10.1016/S00406090(00)01009-9.

[24] F. Erfurth, A. Grimm, J. Palm, T. P. Niesen, F. Reinert, L. Weinhardt, E. Umbach, Direct determination of the band alignment at the ( $\mathrm{Zn}, \mathrm{Mg}) \mathrm{O} / \mathrm{CISSe}$ interface, Appl. Phys. Lett. 98 (14) (2011) 142107-1-142107-3. doi:10.1063/1.3565972.

[25] A. Suryanarayana Reddy, P. Prathap, Y. P. V. Subbaiah, K. T. Ramakrishna Reddy, J. Yi, Growth and physical behaviour of $\mathrm{Zn}_{1-x} \mathrm{Mg}_{x} \mathrm{O}$ films, Thin Solid Films 516 (20) (2008) 7084-7087. doi:10.1016/j.tsf.2007.12.098.

[26] M. Burgelman, P. Nollet, S. Degrave, Modelling polycrystalline semiconductor solar cells, Thin Solid Films 361362 (2000) 527-532. doi:10.1016/S00406090(99)00825-1.

[27] M. Gloeckler, A. L. Fahrenbruch, J. R. Sites, Numerical modeling of CIGS and CdTe solar cells: setting the baseline, in: Third World Conference Photovolt. Energy Convers., Vol. 1, IEEE, 2003, pp. 491-494.

[28] D. Mao, L. H. Feng, Y. Zhu, J. Tang, W. Song, R. Collins, D. L. Williamson, J. U. Trefny, Interdiffusion in polycrystalline thin-film $\mathrm{CdTe} / \mathrm{CdS}$ solar cells, in: AIP
Conference Proceedings, Vol. 353, 1996, pp. 352-359. doi:10.1063/1.49426.

[29] B. A. Aguirre, D. Zubia, R. Ordonez, F. Anwar, H. Prieto, C. A. Sanchez, M. T. Salazar, A. A. Pimentel, J. R. Michael, X. Zhou, J. C. Mcclure, G. N. Nielson, J. L. Cruz-Campa, Selective Growth of CdTe on Nano-patterned CdS via Close-Space Sublimation, Journal of Electronic Materials (7) (2014) 2651-2657. doi:10.1007/s11664-014-3104-7.

[30] X. W. Zhou, D. K. Ward, F. P. Doty, J. A. Zimmerman, B. M. Wong, J. L. Cruz-Campa, G. N. Nielson, J. J. Chavez, D. Zubia, J. C. McClure, A prediction of dislocation-free $\mathrm{CdTe} / \mathrm{CdS}$ photovoltaic multilayers via nano-patterning and composition grading, Prog. Photovoltaics Res. Appl. (2015) 18371846doi:10.1002/pip.2628.

[31] R. Klenk, Characterisation and modelling of chalcopyrite solar cells, Thin Solid Films 387 (12) (2001) 135-140. doi:10.1016/S0040-6090(00)01736-3.

[32] J. Fritsche, S. Gunst, A. Thißen, R. Gegenwart, A. Klein, W. Jägermann, CdTe thin film solar cells: The $\mathrm{CdS} / \mathrm{SnO}_{2}$ front contact, in: Proc. Mat. Res. Soc. Symp., Vol. 668, Cambridge Univ Press, 2001, p. 5.

[33] V. Krishnakumar, K. Ramamurthi, A. Klein, W. Jägermann, Band alignment of differently treated TCO/CdS interface, Thin Solid Films 517 (7) (2009) 2558-2561. doi:10.1016/j.tsf.2008.11.065.

[34] D. W. Niles, D. Rioux, H. Höchst, A photoemission investigation of the $\mathrm{SnO}_{2} / \mathrm{CdS}$ interface: A front contact interface study of CdS/CdTe solar cells, J. Appl. Phys. 73 (9). doi:10.1063/1.352748.

[35] M. G. Helander, M. T. Greiner, Z. B. Wang, W. M. Tang, Z. H. Lu, Work function of fluorine doped tin oxide, J. Vac. Sci. Tech. A 29 (1) (2011) 011019. doi:10.1116/1.3525641.

[36] A. Klein, C. Körber, A. Wachau, F. Säuberlich, Y. Gassenbauer, S. P. Harvey, D. E. Proffit, T. O. Mason, Transparent conducting oxides for photovoltaics: Ma- 
nipulation of Fermi level, work function and energy band alignment, Materials 3 (11) (2010) 4892-4914. doi:10.3390/ma3114892.

[37] D. E. Swanson, R. M. Geisthardt, J. T. McGoffin, J. D. Williams, J. R. Sites, Improved CdTe solar-cell performance by plasma cleaning the TCO layer, IEEE J. Photovoltaics 3 (2) (2013) 838-842. doi:10.1109/JPHOTOV.2013.2244163. 


\begin{tabular}{rcccccc} 
Oxide & $\phi[\mathbf{e V}]$ & $\mathbf{E}_{F}-\mathbf{E}_{V}[\mathbf{e V}]$ & $\chi[\mathbf{e V}]$ & $\mathbf{d}[\mathbf{n m}]$ & $\rho[\Omega-\mathbf{c m}]$ & alloy composition [at\%] \\
\hline $\mathrm{SnO}_{2}: \mathrm{Zn}($ low $)$ & 4.1 & 3.9 & 4.4 & 150 & 5 & 0.8 \\
$\mathrm{SnO}_{2}: \mathrm{Ga}$ & 4.3 & 3.9 & 4.6 & 150 & 10 & 0.9 \\
$\mathrm{SnO}_{2}: \mathrm{In}$ & 4.4 & 3.8 & 4.6 & 150 & 80 & 0.5 \\
$\mathrm{SnO}_{2}: \mathrm{Zn}(\mathrm{high})$ & 4.7 & 3.7 & 4.8 & 150 & 100 & 3.3 \\
$\mathrm{SnO}_{2}: \mathrm{F}, \mathrm{N}$ & 4.9 & 3.9 & 5.2 & 95 & 100 & 0.2 \\
$\mathrm{SnO}_{2}$ & 5.0 & 3.9 & 5.3 & 150 & no data & 0 \\
$\mathrm{SnO}_{2}: \mathrm{F}(\mathrm{TCO})$ & 5.0 & 3.9 & 5.3 & 400 & $5 \cdot 10^{-4}$ & 0.3 \\
$\mathrm{ZnO}$ & 4.3 & 3.3 & 4.4 & 50 & $\approx 10^{7}$ & 0 \\
$\mathrm{Mg}_{x} \mathrm{Zn}_{1-x} \mathrm{O}$ & 4.0 & 3.8 & 4.1 & 50 & $\approx 10^{7}$ & 23
\end{tabular}

Table 1: UPS band measurements of various oxides deposited on FTO are summarized. The valence band positions and material bandgaps were used to calculate electron affinity. 


\begin{tabular}{cccc} 
Parameter & Oxide & CdS & CdTe \\
\hline $\mathrm{x}[\mathrm{nm}]$ & 150 & none or 50 & 2500 \\
$\mathrm{E}_{G}[\mathrm{eV}]$ & 3.6 & 2.4 & 1.5 \\
$\chi[\mathrm{eV}]$ & varies & 4.5 & 4.4 \\
$\varepsilon / \varepsilon_{0}$ & 9 & 10 & 9.4 \\
$\mathrm{~N}_{C}\left[\mathrm{~cm}^{-3}\right]$ & $2.2 \cdot 10^{18}$ & $2.2 \cdot 10^{18}$ & $8.0 \cdot 10^{17}$ \\
$\mathrm{~N}_{V}\left[\mathrm{~cm}^{-3}\right]$ & $1.8 \cdot 10^{19}$ & $1.8 \cdot 10^{19}$ & $1.8 \cdot 10^{19}$ \\
$\mu_{e}\left[\mathrm{~cm}^{2} / \mathrm{V} \cdot \mathrm{s}\right]$ & 1 & 100 & 320 \\
$\mu_{h}\left[\mathrm{~cm}^{2} / \mathrm{V} \cdot \mathrm{s}\right]$ & 25 & 25 & 40 \\
$\tau_{n}, \tau_{p}[\mathrm{~ns}]$ & 0.1 & 0.1 & 2
\end{tabular}

$\mathrm{n}$ or $\mathrm{p}\left[\mathrm{cm}^{-3}\right] \quad \mathrm{n}=1 \cdot 10^{18} \quad \mathrm{n}=1 \cdot 10^{15} \quad \mathrm{p}=2 \cdot 10^{14}$

\section{Oxide/CdTe CdS/CdTe CdTe Back}

\begin{tabular}{cccc}
\hline $\mathrm{S}_{n}, \mathrm{~S}_{p}[\mathrm{~cm} / \mathrm{s}]$ & $10^{7}$ & $10^{5}$ & $10^{7}$ \\
$\mathrm{Q}_{i f}\left[\mathrm{~cm}^{-2}\right]$ & $-2 \cdot 10^{12}$ & - & -
\end{tabular}

Table 2: 1-d modeling baseline parameters used for SCAPS simulation of HRT and window material property effects.
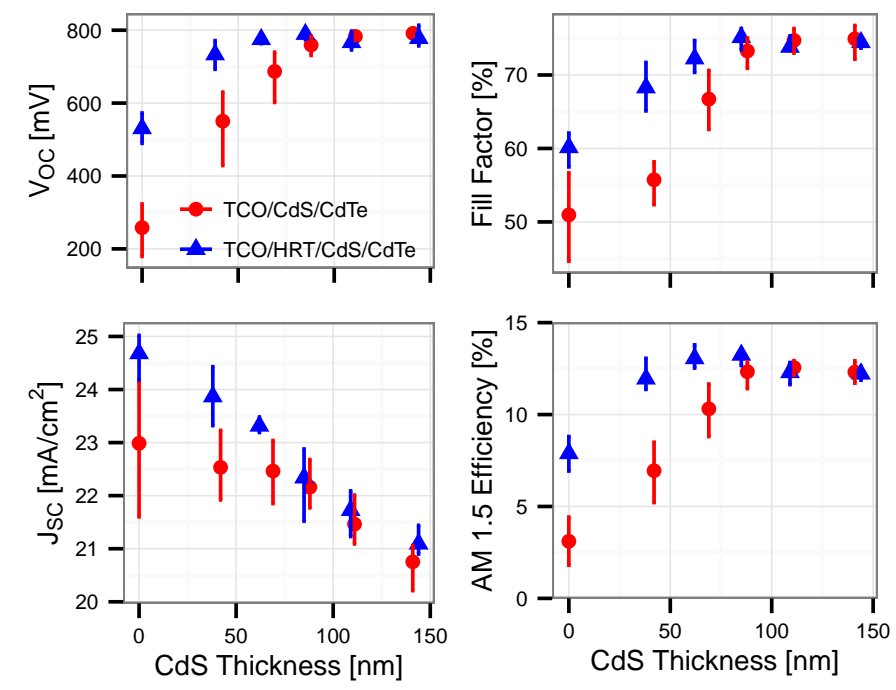

Figure 1: Efficiency parameters of cells made with varying sublimated CdS thickness, adapted from previous work [16]. Cells were made with $\mathrm{TCO} / \mathrm{CdS} / \mathrm{CdTe}$ and TCO/HRT/CdS/CdTe structures. The highest efficiency for a cell with the optimum $\mathrm{Zn}$-doped $\mathrm{SnO}_{2}$ HRT occurs with slightly thinner CdS than for devices without HRT. 


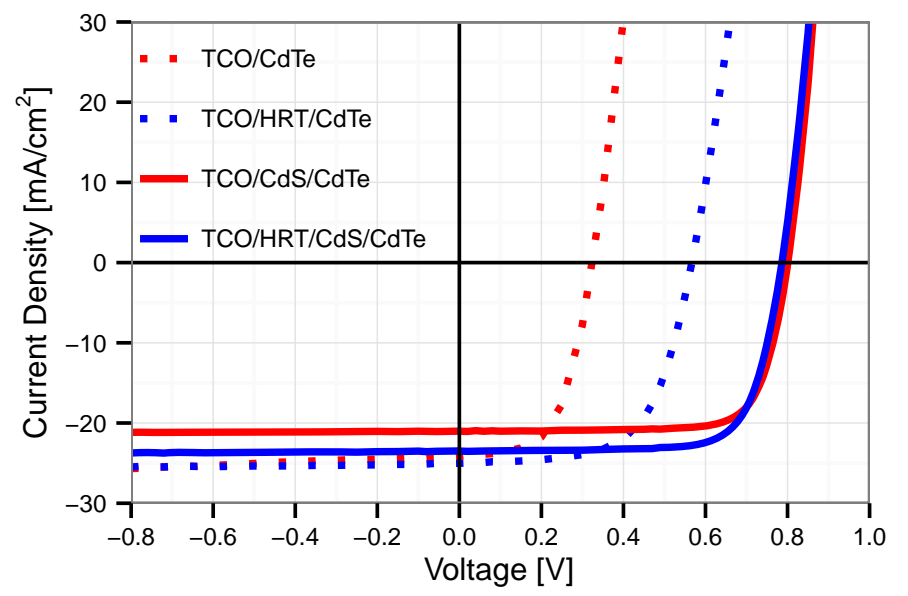

Figure 2: J-V curves of highest-efficiency cells with the TCO/CdTe, TCO/HRT/CdTe, TCO/CdS/CdTe, and TCO/HRT/CdS/CdTe structures using the $\mathrm{Zn}$-doped $\mathrm{SnO}_{2} \mathrm{HRT}$. The HRT allows additional short circuit current from thinner CdS, with minimal loss in $\mathrm{V}_{O C}$. Maximum efficiency was improved from $12.9 \%$ to $13.8 \%$.
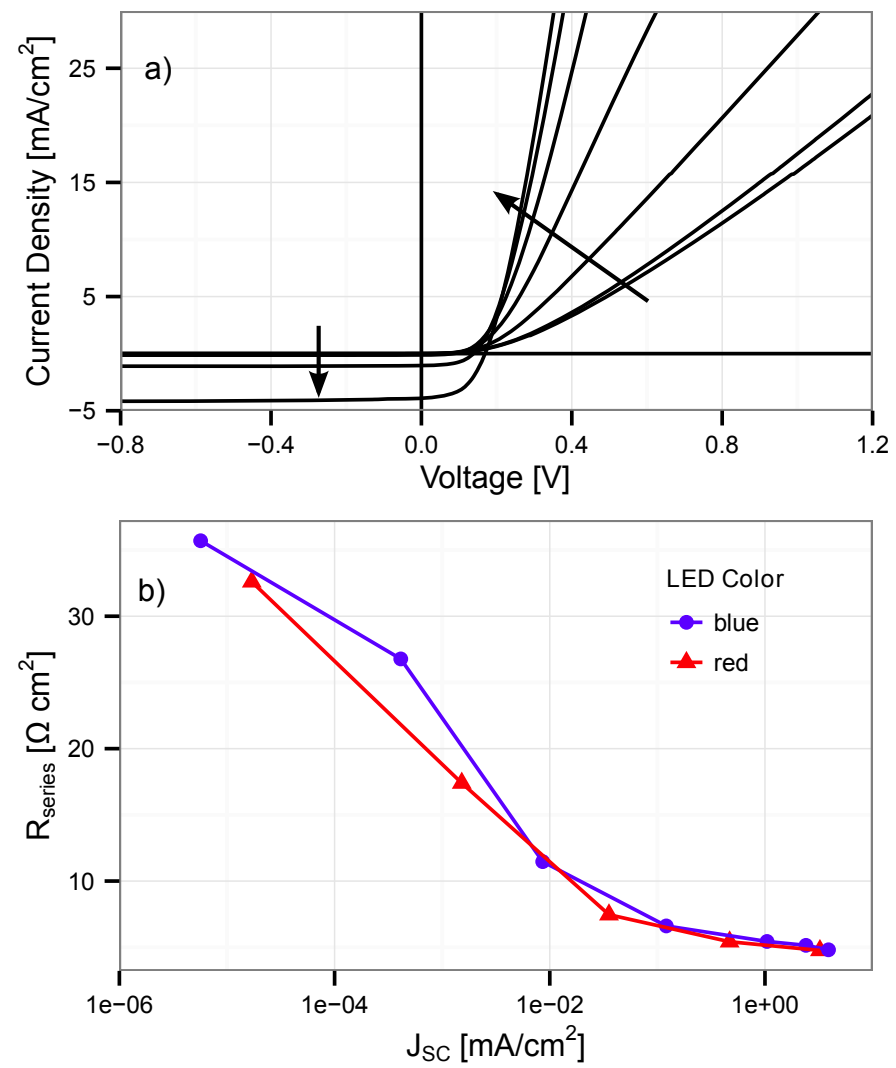

Figure 3: Series resistance of a device with the TCO/CdTe structure. a) Each curve has a different level of blue LED illumination (over several orders of magnitude). Series resistance is reduced drastically with increasing illumination. b) The dependence of series resistance on $\mathrm{J}_{S C}$ (a measure of illumination level) is comparable for illumination with red and blue light. 

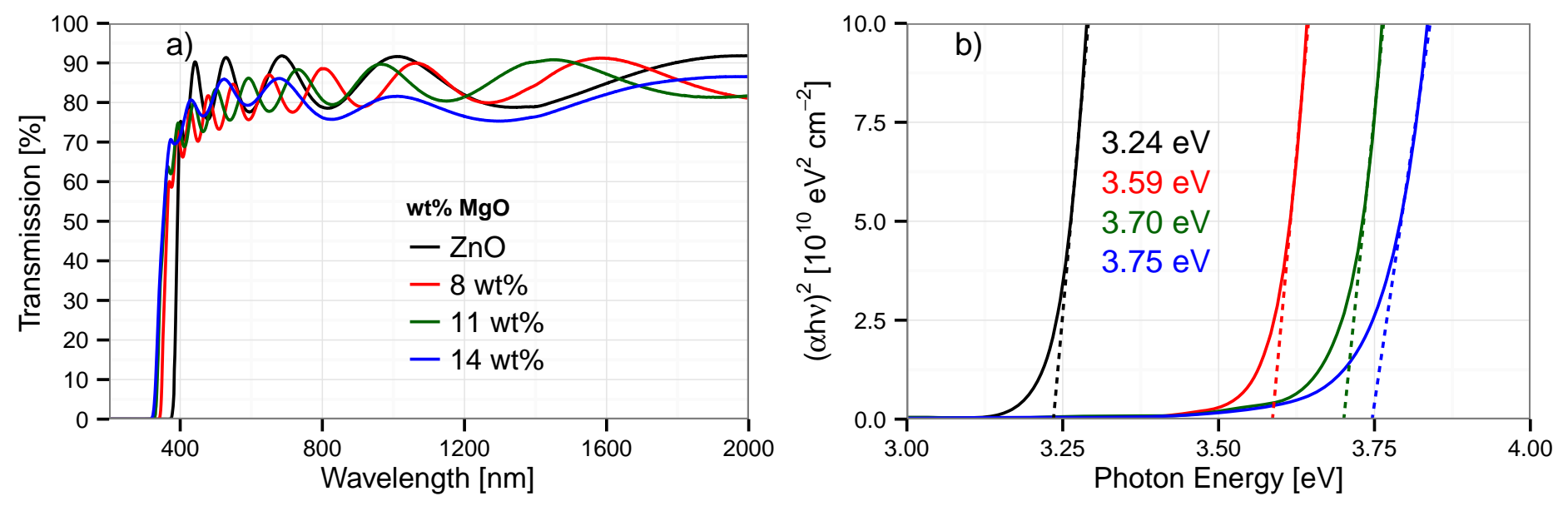

Figure 4: a) The transmission of the films remains high over a wide wavelength range. b) The Tauc plot shows increasing optical bandgap with magnesium content.
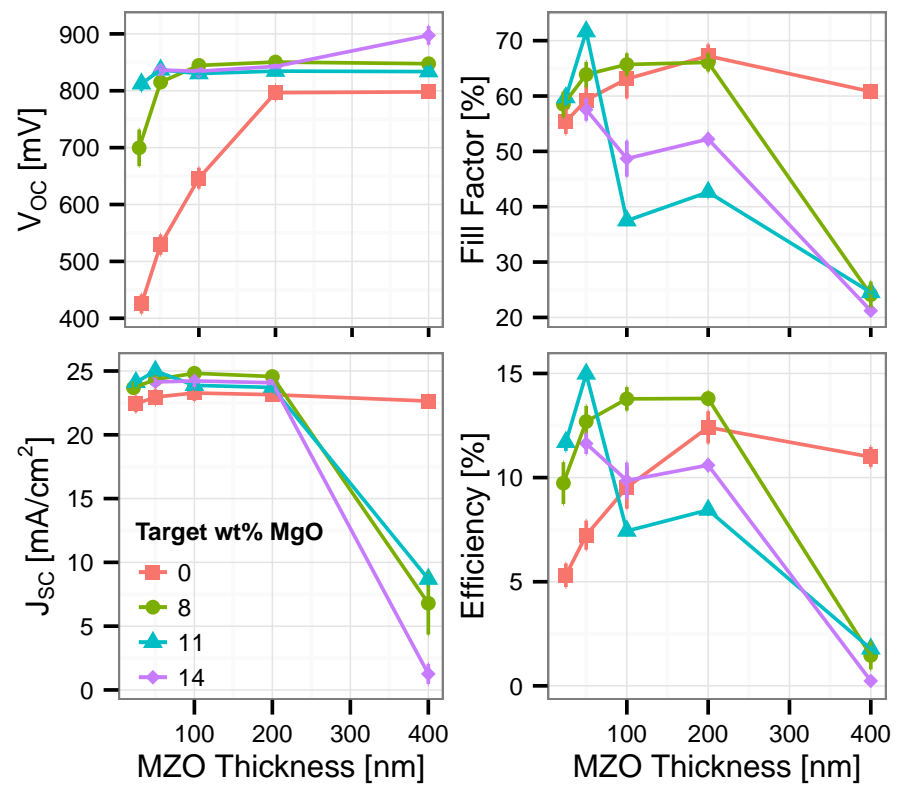

Figure 5: Parameters are shown for devices made with $\mathrm{Mg}_{x} \mathrm{Zn}_{1-x} \mathrm{O}$ layers on TEC 10 glass with no CdS layer. With higher magnesium, high $\mathrm{V}_{O C}$ can be achieved with thinner layers but fill factor is reduced to due a kink in the $\mathrm{J}-\mathrm{V}$ curve. Error bars show the $95 \%$ confidence interval. 


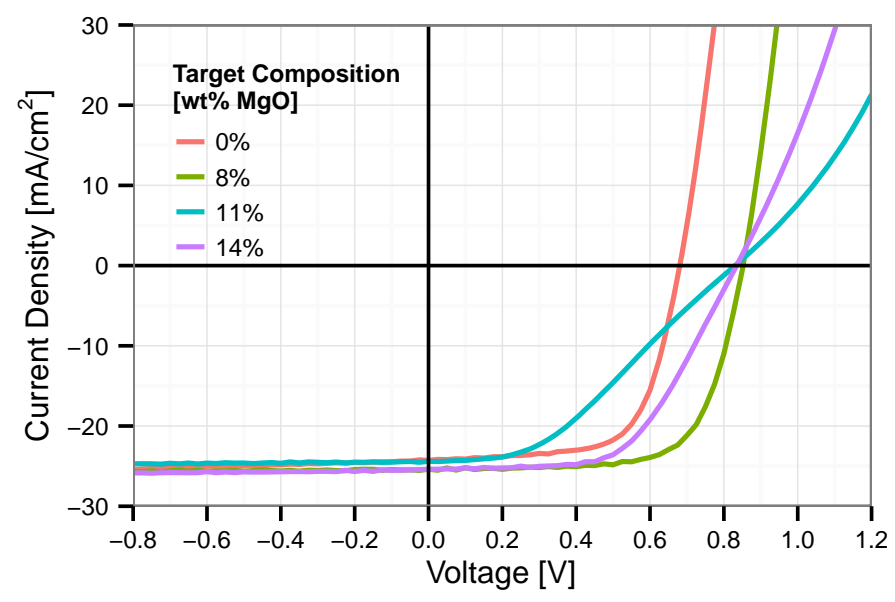

Figure 6: The J-V curves of the center devices from the $\mathrm{Mg}_{x} \mathrm{Zn}_{1-x} \mathrm{O}$ thickness-composition optimization for 100-nm thick MZO layers. The $\mathrm{ZnO}$ sample has low $\mathrm{V}_{O C}$, while the samples with higher magnesium composition have high $\mathrm{V}_{O C}$ and a kink; there is variability in the kink, with a trend toward a larger kink and lower fill factor with higher magnesium content and thicker MZO layers.

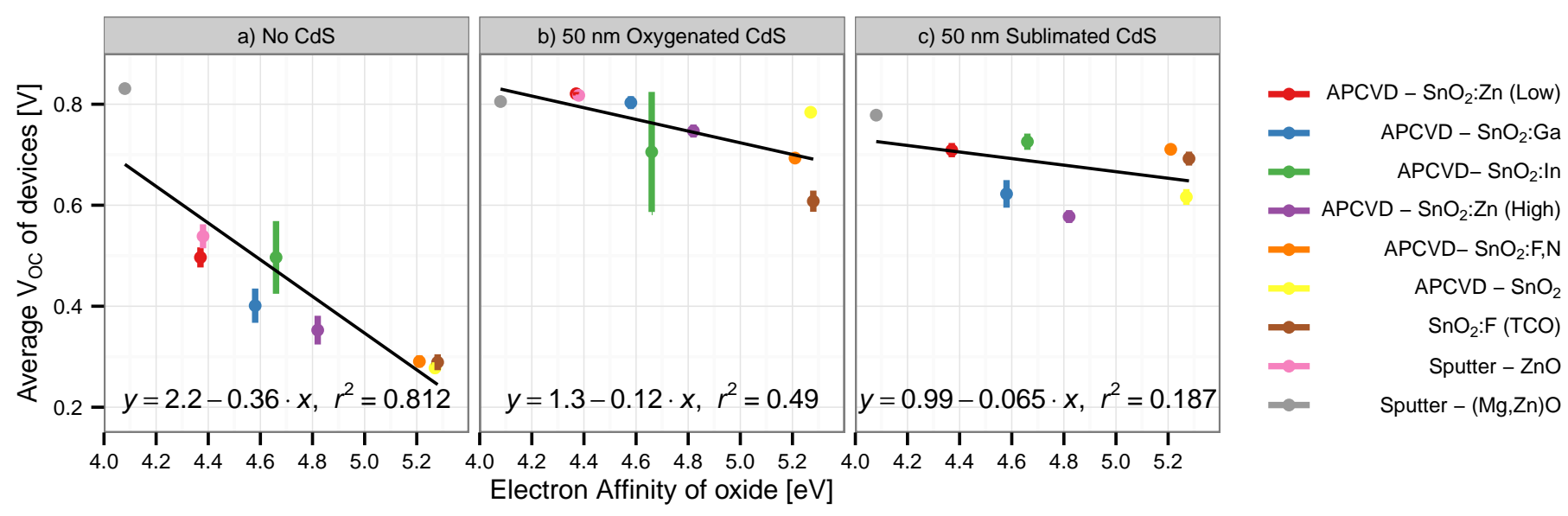

Figure 7: Comparing UPS measurements of electron affinity with device results, a) when no CdS is deposited and CdTe is grown on oxides, there is a strong correlation between $\mathrm{V}_{O C}$ and electron affinity. $\mathrm{b}$ ) the correlation is somewhat weaker when a resistive oxygenated CdS window layer is used between the oxide and CdTe; and c) the dependence is quite weak but present when sublimated CdS was used. 


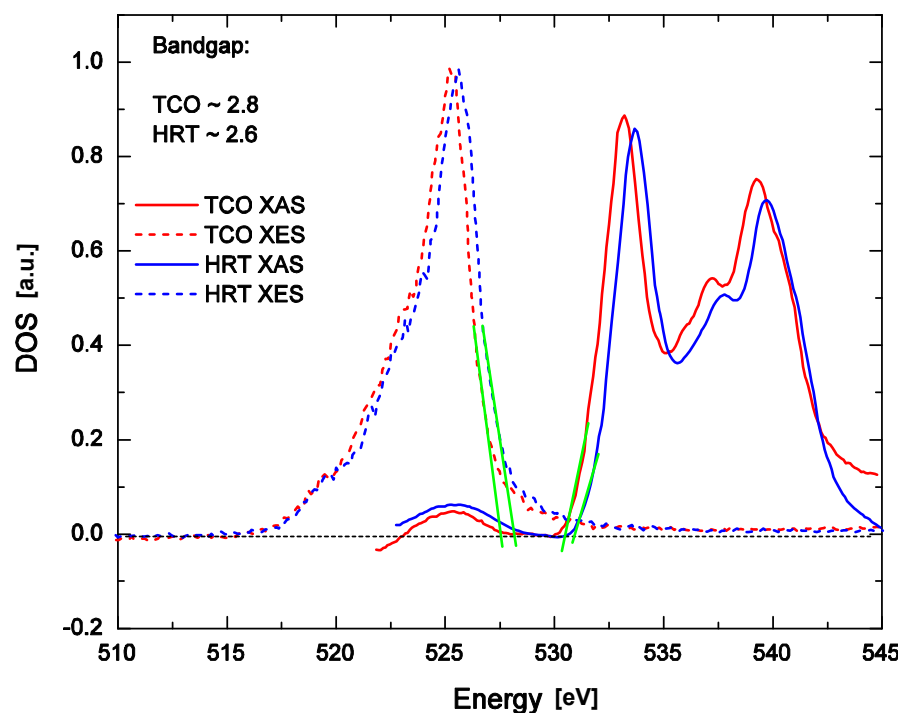

Figure 8: Using X-ray emission spectroscopy to probe the valence band and X-ray absorption spectroscopy to probe the conduction band, a clear shift to higher photon energy is seen for the HRT versus the TCO, implying lower electron affinity.
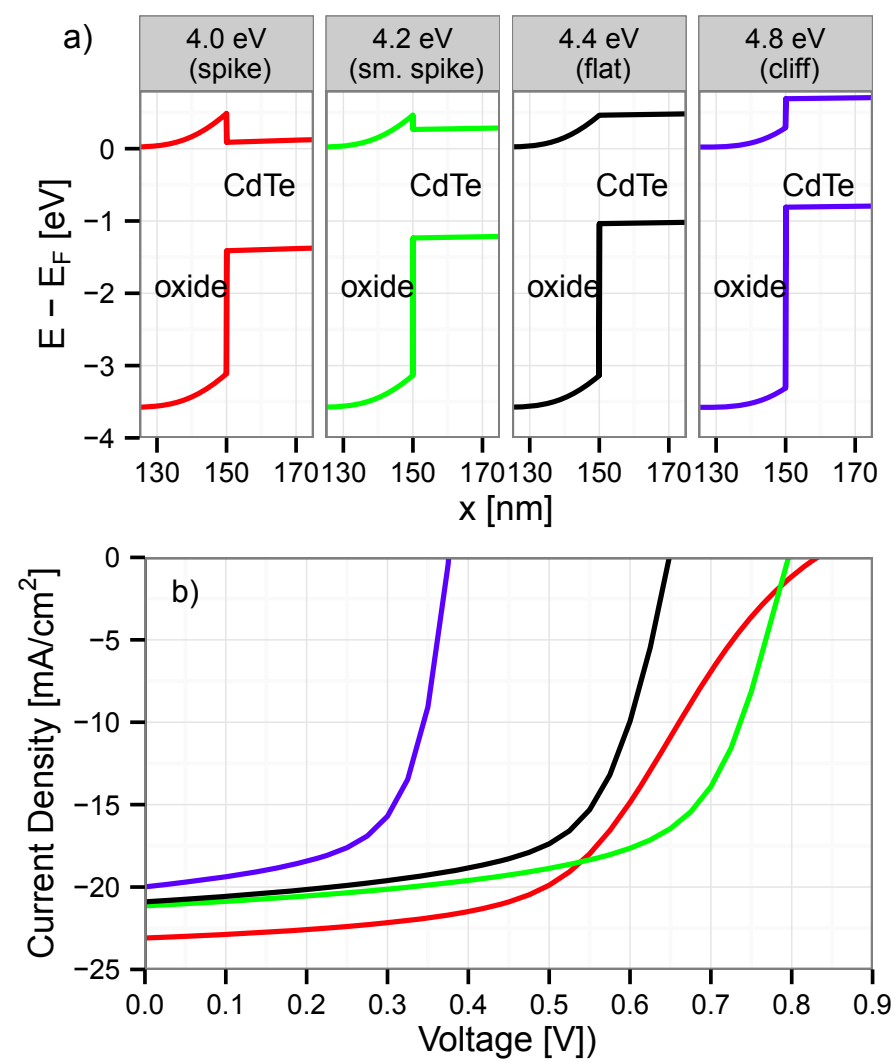

Figure 9: a) For devices with no CdS, the conduction band offset goes from positive to negative as the electron affinity of the oxide increases. This causes the CdTe conduction band minimum to move away from the Fermi level. b) The effect of electron affinity on device quality is clearly seen in the model results. With a small spike the $\mathrm{V}_{O C}$ can be improved from a flat conduction band offset, and with a large spike (low electron affinity) a kink appears in the J-V curve. 


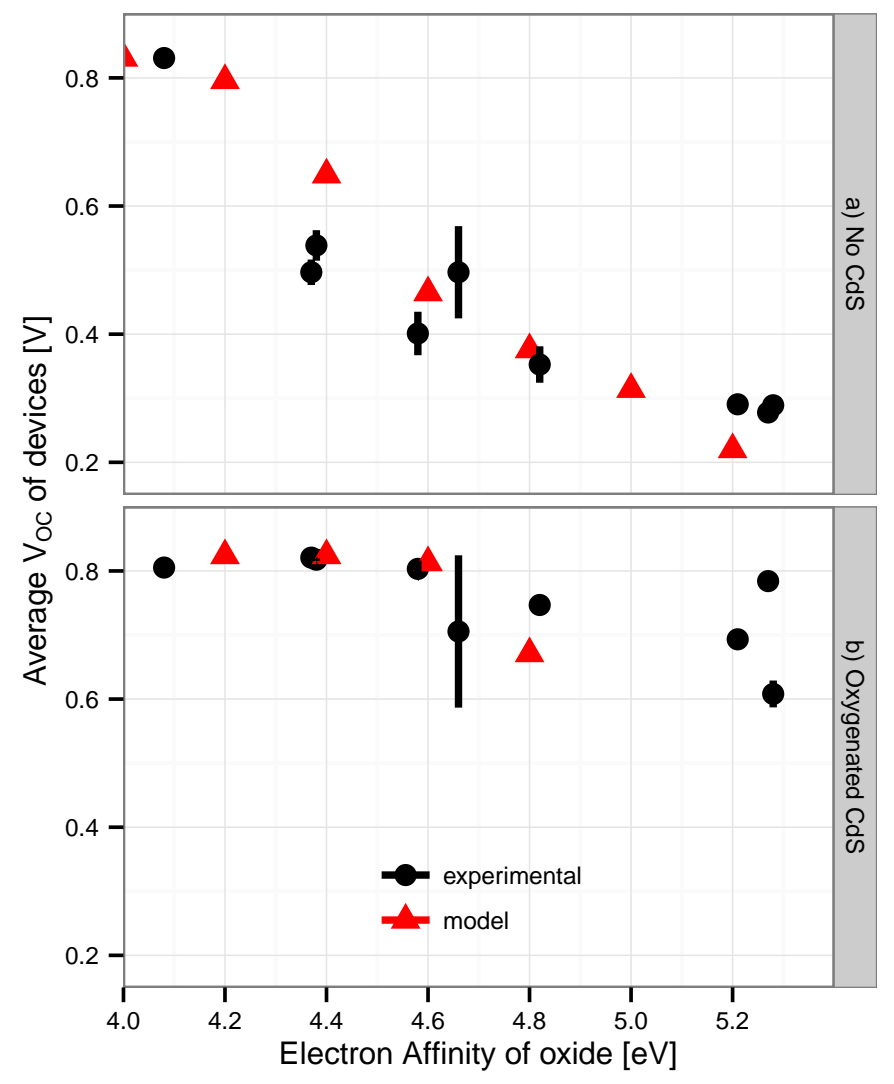

Figure 10: The experimental band measurements and device results are compared to the model a) For devices with no $\mathrm{CdS}$ and b) for devices with $50 \mathrm{~nm}$ CdS. The voltage is less sensitive to small changes in conduction band offset, and the oxide/CdS interface is pinned in a limited range of conduction band offset. 